Pacific Journal of Mathematic 


\section{HITTING TIMES FOR TRANSIENT STABLE PROCESSES}

\section{S. C. PORT}

In this paper we explicitly find the asymptotic behavior, for large $t$, of the probability that a transient $d$-dimensional stable process first (last) hits a bounded Borel set during the time interval $(t, \infty)$.

Assume that $X(t)$ is a stable process on $R^{d}$ ( $d$-dimensional Euclidean space) having exponent $\alpha<d$ and normalized so that the paths are right continuous with left-hand limits at every point. Assume further that $[X(t)-X(0)] t^{-1 / \alpha}$ is distributed like $X(1)-X(0)$, and moreover, that $X(1)-X(0)$ has a genuinely $d$-dimensional distribution on $R^{d}$. [In particular, every symmetric stable process on $R^{d}$ with 0 mean (when it exists) satisfies these conditions.]

From these assumptions it follows that $X(t)-X(0)$ has a bounded, continuous density, $f(t, x)$, which satisfies the well-known scaling property

$$
f(t, x)=t^{-\alpha / \alpha} f\left(1, t^{-1 / \alpha} x\right) .
$$

For a Borel (more generally, analytic) set $B \subset R^{d}$, let

$$
V_{B}=\inf \{t>0: X(t) \in B\}
$$

denote the first hitting time of $B$. As usual we set $V_{B}=\infty$ if

$$
X(t) \notin B
$$

for all $t>0$. Our main purpose in this note is to establish the following.

TheOREM 1. Let $B$ be a bounded Borel (or analytic) subset of $R^{d}$. Then under the above assumptions on $X(t)$,

$$
\lim _{t \rightarrow \infty} t^{(d / \alpha)-1} P_{x}\left(t<V_{B}<\infty\right)=P_{x}\left(V_{B}=\infty\right) C(B)\left[\frac{d}{\alpha}-1\right]^{-1} f(1,0),
$$

where $C(B)$ is the natural capacity of $B$.

Previously, (by using a different method) Joffe [2] established this result for symmetric processes with $(d / 2)<\alpha<1$ when $B$ has a nonempty interior, and Spitzer [4] (Lemma, p. 114) established this result for arbitrary compact $B$ in the case of 3-dimensional Brownian motion. In the case of recurrent stable processes the analogue of Theorem 1 can be found in [3]. 

easier

It is interesting to compare Theorem 1 with the following, much

THEOREM 2. Let

$$
T_{B}=\inf \{t \geqq 0: X(s) \notin B, \text { all } s>t\}
$$

be the last hitting time of $B$. Then under the same conditions as Theorem 1,

$$
\lim _{t \rightarrow \infty} t^{(d / \alpha)-1} P_{x}\left(T_{B}>t\right)=C(B)\left[\frac{d}{\alpha}-1\right]^{-1} f(1,0) .
$$

\section{Proofs.}

Proof of. Theorem 1. A first passage decomposition yields

$$
\begin{aligned}
& P_{x}\left(t<V_{B}<\infty\right)=\int_{R^{d}} P_{x}\left(V_{B}>t, X(t) \in d y\right) P_{y}\left(V_{B}<\infty\right) \\
= & \int_{R^{d}}\left[f(t, y-x)-\int_{0}^{t} \int_{\bar{B}} H_{B}(x, d s, d z) f(t-s, y-z)\right] P_{y}\left(V_{B}<\infty\right) d y,
\end{aligned}
$$

where here and in the following,

$$
H_{B}(x, d s, d z)=P_{x}\left(V_{B} \in d s, X(s) \in d z\right),
$$

and $\bar{B}$ is the closure of $B$. But it is a known fact ([1] Prop. 18.4) that there is a measure, $e_{B}(d y)$, with support contained in $\bar{B}$ (the capacitary measure of $B$ ) and finite total mass $C(B)$ (the capacity of $B$ ), such that

$$
P_{y}\left(V_{B}<\infty\right)=\int_{\vec{B}} g(u-y) e_{B}(d u),
$$

where

$$
g(x)=\int_{0}^{\infty} f(t, x) d t
$$

is the potential kernel density for the process $X(t)$. Setting

$$
R(t, x)=\int_{t}^{\infty} f(s, x) d s
$$

and using the fact that

$$
\int_{R^{d}} f(t, y-x) g(u-y) d y=R(t, u-x),
$$

we obtain from (2.1) that 


$$
\begin{gathered}
P_{x}\left(t<V_{B}<\infty\right) \\
\int_{\bar{B}}\left[R(t, y-x)-\int_{\bar{B}} \int_{0}^{t} H_{B}(x, d s, d z) R(t-s, y-z)\right] e_{B}(d y) .
\end{gathered}
$$

From the scaling property (1.1) and the fact that $f(1, x)$ is continuous, we see that $\lim _{t \rightarrow \infty} t^{d / \alpha} f(t, x)=f(1,0)$, uniformly in $x$ on compacts, and thus

$$
\lim _{t \rightarrow \infty} t^{(d / \alpha)-1} R(t, x)=f(1,0)\left[\frac{d}{\alpha}-1\right]^{-1},
$$

uniformly in $x$ on compacts. Set

$$
R(t)=t^{-(d / \alpha)+1}\left[\frac{d}{\alpha}-1\right]^{-1}
$$

Then from (2.5),

$$
\lim _{t \rightarrow \infty} \int_{\bar{B}} \frac{R(t, y-x)}{R(t)} e_{B}(d y)=f(1,0) C(B),
$$

and

$$
\begin{aligned}
& \lim _{T \rightarrow \infty} \lim _{t \rightarrow \infty} \int_{0}^{T}\left[\int_{\bar{B}} \int_{\bar{B}} H_{B}(x, d s, d z) R(t-s, y-z) e_{B}(d y)\right] R(t)^{-1} \\
= & \lim _{T \rightarrow \infty} \int_{0}^{T} H_{B}(x, d s, \bar{B}) C(B) f(1,0)=P_{x}\left(V_{B}<\infty\right) C(B) f(1,0) .
\end{aligned}
$$

From (2.4), we see that in order to complete the proof it suffices to show

(2.8) $\quad \lim _{T \rightarrow \infty} \limsup _{t \rightarrow \infty} R(t)^{-1} \int_{T}^{t} \int_{\bar{B}} \int_{\bar{B}} H_{B}(x, d s, d z) R(t-s, y-z) e_{B}(d y)=0$.

To accomplish this, decompose $\int_{T}^{t}$ as $\int_{T}^{t / 2}+\int_{t / 2}^{t-T}+\int_{t-T}^{t}$. Since

$$
\sup _{x} f(1, x)=K<\infty \text {, }
$$

it follows from the scaling property that $R(t, x) \leqq K R(t)$ for all $t>0$. Setting $A=K C(B)$, we obtain

$$
\int_{T}^{t / 2} \leqq A \int_{T^{T}}^{t / 2} P_{x}\left(V_{B} \in d s\right) R(t-s) \leqq A R(t / 2) P_{x}\left(T<V_{B}<\infty\right),
$$

and thus

$$
\lim _{r} \lim _{t} \sup R(t)^{-1} \int_{T}^{t / 2}=0
$$

Next observe that 


$$
\int_{t / 2}^{t-T} \leqq A \int_{t / 2}^{t-T} P_{x}\left(V_{B} \in d s\right) R(t-s) \leqq A R(T) P_{x}\left(t / 2<V_{B}<\infty\right) .
$$

By (2.4) this last term is dominated by $A^{2} R(T) R(t / 2)$, and thus

$$
\lim _{T} \lim \sup _{t} R(t)^{-1} \int_{t / 2}^{t-T}=0 \text {. }
$$

Finally, from (2.2) we see that

$$
\int_{t-T^{T}}^{t} \leqq \int_{t-T^{\top}}^{t} \int_{\bar{B}} H_{B}(x, d s, d z) \int_{\bar{B}} g(y-z) e_{B}(d y) \leqq \int_{t-T^{T}}^{t} P_{x}\left(V_{B} \in d s\right) .
$$

But

$$
\begin{aligned}
& P_{x}\left(t-T<V_{B} \leqq t\right)=\int_{R^{d}} P_{x}\left(V_{B}>t-T, X(t-T) \in d y\right) P_{y}\left(V_{B} \leqq T\right) \\
& \leqq \int_{R^{d}} f(t-T, y-x) P_{y}\left(V_{B} \leqq T\right) d y \leqq K(t-T)^{-d / \alpha} \int_{R^{d}} P_{y}\left(V_{B} \leqq T\right) d y .
\end{aligned}
$$

Since the paths $X(t)$ are bounded a.s. on $[0, T]$, we see that for each $T$ there is a sphere $S_{T} \supset \bar{B}$, such that $P_{y}\left(X(t) \in S_{T}\right) \geqq 1 / 2$ for all $t \leqq T$ and $y \in \bar{B}$. But then

$$
\begin{aligned}
& \left|S_{T^{\prime}}\right|=\int_{R^{d}} P_{x}\left(X(T) \in S_{T}\right) d x \geqq \int_{R^{d}} d x \int_{0}^{T} \int_{\bar{B}} H_{B}(x, d s, d y) P_{y}\left(X(T-s) \in S_{T^{\prime}}\right) \\
& \geqq \frac{1}{2} \int_{R^{d}} P_{x}\left(V_{B} \leqq T\right) d x .
\end{aligned}
$$

Thus

$$
\lim _{t \rightarrow \infty} R(t)^{-1} \int_{t-T}^{t}=0
$$

This completes the proof.

Proof of Theorem 2. Clearly

$$
P_{x}\left(T_{B}>t\right)=\int_{R^{d}} f(t, y-x) P_{y}\left(V_{B}<\infty\right) d y .
$$

Using (2.2) and (2.3) we see that

$$
P_{x}\left(T_{B}>t\right)=\int_{\bar{B}} R(\mathrm{t}, y-x) e_{B}(d y),
$$

from which the theorem follows.

REMARK. When $d / 2<\alpha<d$, it is possible to establish Theorem 1 by a much simpler argument. Set 


$$
\begin{aligned}
& Q_{B}^{\lambda}(x)=\int_{0}^{\infty} e^{-\lambda t} P_{x}\left(t<V_{B}<\infty\right) d t \\
& H_{B}^{\lambda}(x, d y)=\int_{0}^{\infty} e^{-\lambda t} P_{x}\left(V_{B} \in d t, x(t) \in d y\right)
\end{aligned}
$$

and

$$
R^{\lambda}(x)=\int_{0}^{\infty} R(t, x) e^{-\lambda t} d t
$$

Then from (2.4) we obtain

$$
Q_{B}^{\lambda}(x)=\int_{\bar{B}}\left[R^{\lambda}(y-x)-\int_{\bar{B}} H_{B}^{\lambda}(x, d z) R^{\lambda}(y-z)\right] e_{B}(d y) .
$$

It follows from (2.5) that uniformly in $x$ on compacts,

$$
\lim _{\lambda \downarrow 0} R^{\lambda}(x) \lambda^{2-d / \alpha}=f(1,0)\left[\frac{d}{\alpha}-1\right]^{-1} \Gamma(2-d / \alpha) .
$$

Consequently, from (2.9), we see that

$$
\lim _{\lambda \downarrow 0} Q_{B}^{\lambda}(x) \lambda^{2-d / \alpha}=f(1,0) C(B) P_{x}\left(V_{B}=\infty\right)\left[\frac{d}{\alpha}-1\right]^{-1} \Gamma(2-d / \alpha) .
$$

An appeal to Karamata's theorem, and the fact that $P_{x}\left(t<V_{B}<\infty\right)$ is monotone in $t$, then yields (1.2).

The above argument breaks down when $\alpha<d / 2$ since

$$
\lim _{\lambda \downarrow 0} R^{\lambda}(x)<\infty,
$$

and the more complicated proof given previously is needed.

\section{REFERENCES}

1. G. A. Hunt, Markoff processes and potentials III, Illinois J. Math. 2 (1958), 151-213.

2. A. Joffe, Sojourn Time for Stable Processes, Thesis, cornell U., 1959.

3 , S. C. Port, Hitting times and potentials for recurrent stable processes, J. D' Analyse Mathematique (to appear)

4. F. Spitzer, Electrostatic capacity, heat flow, and Brownian motion, Z. Warscheinlichk 3, (1964).

Received June 30, 1966. This research is sponsored by the United States Air Force under Project RAND-Contract No. AF 49 (638)-1700 monitored by the Directorate of Development Plans, Deputy Chief of Staff, Research and Development, $\mathrm{Hq}$ USAF. 



\section{PACIFIC JOURNAL OF MATHEMATICS}

\section{EDITORS}

H. SAMELSON

Stanford University

Stanford, California

J. P. JANS

University of Washington

Seattle, Washington 98105
J. DugundJI

University of Southern California

Los Angeles, California 90007

RICHARD ARENS

University of California

Los Angeles, California 90024

\section{ASSOCIATE EDITORS}

E. F. BECKENBACH

B. H. NeumanN

F WolF

K. YOSIDA

\section{SUPPORTING INSTITUTIONS}

UNIVERSITY OF BRITISH COLUMBIA

CALIFORNIA INSTITUTE OF TECHNOLOGY

UNIVERSITY OF CALIFORNIA

MONTANA STATE UNIVERSITY

UNIVERSITY OF NEVADA

NEW MEXICO STATE UNIVERSITY

OREGON STATE UNIVERSITY

UNIVERSITY OF OREGON

OSAKA UNIVERSITY

UNIVERSITY OF SOUTHERN CALIFORNIA
STANFORD UNIVERSITY

UNIVERSITY OF TOKYO

UNIVERSITY OF UTAH

WASHINGTON STATE UNIVERSITY

UNIVERSITY OF WASHINGTON

AMERICAN MATHEMATICAL SOCIETY CHEVRON RESEARCH CORPORATION TRW SYSTEMS

NAVAL ORDNANCE TEST STATION

Printed in Japan by International Academic Printing Co., Ltd., Tokyo Japan 


\section{Pacific Journal of Mathematics}

\section{Vol. 21, No. $1 \quad$ November, 1967}

Friedrich-Wilhelm Bauer, Der Hurewicz-Satz................... 1

D. W. Dubois, A note on David Harrison's theory of preprimes . ......... 15

Bert E. Fristedt, Sample function behavior of increasing processes with stationary, independent increments ..................... 21

Minoru Hasegawa, On the convergence of resolvents of operators....... 35

Søren Glud Johansen, The descriptive approach to the derivative of a set function with respect to a $\sigma$-lattice ....................... 49

John Frank Charles Kingman, Completely random measures ............ 59

Tilla Weinstein, Surfaces harmonically immersed in $E^{3} \ldots \ldots \ldots \ldots \ldots . . \ldots 9$

Hikosaburo Komatsu, Fractional powers of operators. II. Interpolation spaces ......................................... 89

Edward Milton Landesman, Hilbert-space methods in elliptic partial differential equations ...................................... 113

O. Carruth McGehee, Certain isomorphisms between quotients of a group algebra ........................................ 133

DeWayne Stanley Nymann, Dedekind groups .................. 153

Sidney Charles Port, Hitting times for transient stable processes ......... 161

Ralph Tyrrell Rockafellar, Duality and stability in extremum problems involving convex functions . ............................ 167

Philip C. Tonne, Power-series and Hausdorff matrices . . .............. 189 